\title{
Wandering Chinese fossil turns up at museum
}

Rex Dalton, San Diego

A controversial Chinese dinosaur fossil, which has meandered for years through the international underground world of dealers, has been bought by a leading German museum, the institution's director said last week.

The psittacosaurid fossil — with a tail clad in spines reminiscent of the quills of a porcupine, never before seen on such specimens - is now at the Naturmuseum Senckenberg in Frankfurt, acknowledged palaeontologist Fritz Steininger. The specimen was purchased this summer from a German dealer, Ulrich Leonhardt, for around US $\$ 200,000$, which is being paid in instalments, said Steininger.

Some prominent palaeontologists believe that the fossil was smuggled out of China, and the propriety of its purchase by the Senckenberg is expected to stir intense debate in the palaeontological community.

Many major museums would have nothing to do with such a specimen, because their rules prevent them from handling fossils of questionable provenance. For instance, the American Museum of Natural History in New York wouldn't allow the specimen in the door, says palaeontology curator Mark Norell. Norell, who works extensively in Asia, says the fossil has been "stolen from China".

Steininger took issue with such an assessment. He says his museum has proper German importation documents and exportation records from the United States, where he said Leonhardt bought it. But Steininger would not discuss any authenticating papers from China.

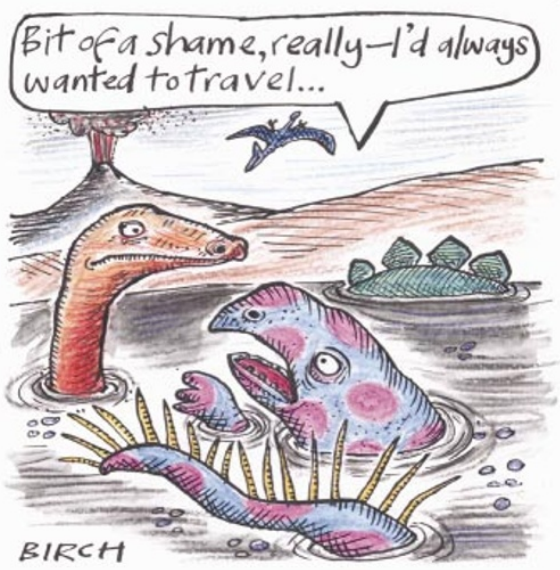

"We have requests from people to come and work on the specimen," says Steininger. "Everyone who is entitled to can study it. We are trying to do our best."

The museum is reconstructing an almost-complete fossil of the animal, which was at least a metre long and lived more than 100 million years ago. The quills on its tail seem to be different from the feather-like integument found in other dinosaurs. The existence of a dinosaur with such unusual integumentary structures will provoke considerable interest among palaeontologists.

But Senckenberg scientists may find it difficult to publish their results in a reputable journal, given the fossil's background. Most journals require records documenting a specimen, such as a museum number. Historically, peer reviewers for leading journals have recommended rejecting manuscripts on specimens lacking such a number.
Steininger revealed that the fossil was at his museum after learning that Nature was preparing an article on its globe-trotting trail into the hands of the dealer, whose firm, Leonhardt \& Partner, is based in Kirchheim, Germany. Two years ago, before it was bought by the Senckenberg, Leonhardt allowed an Italian dealer to take the specimen to the Museo Civico di Storia Naturale in Milan, Italy, for analysis (see Nature 412, 844; 2001).

The dealer, Flavio Bacchia of the Stone Age shop in Trieste, Italy, said Leonhardt returned to Germany with the specimen after Milan scientists learned of the fossil's significance. Earlier this year, a palaeontologist spotted the crated fossil in a vehicle in a parking lot near the University of Tübingen in Germany, being offered for sale for $\$ 300,000$. Leonhardt declined to be interviewed.

Previously, the specimen had made its way around the world, first surfacing some three years ago at a fossil and mineral show in Tucson, Arizona. A dealer there sold it to an American museum, which later returned it. The dealer then sold it to Leonhardt, said Steininger.

When the specimen was in Milan last year, it was examined by palaeontologist Eric Buffetaut of the CNRS, France's national research agency. Realizing its importance, Buffetaut tried unsuccessfully to organize its repatriation to China. A retired Chinese palaeontologist from Beijing's Institute of Vertebrate Paleontology and Paleoanthropology visited Milan to negotiate its return, but failed to do so (see Nature 414, 147; 2001).

\section{NASA engages outside help for mission to Pluto}

\section{Tony Reichhardt, Washington}

For the first time ever, NASA has asked an outside laboratory to lead a reconnaissance mission to an unexplored planet.

The space agency earlier this year funded two feasibility studies for a mission to Pluto.

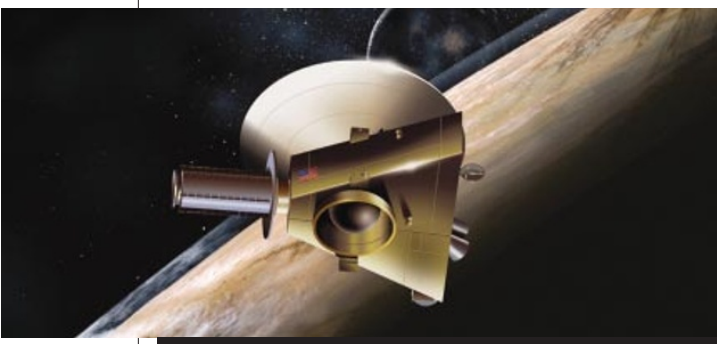

Fresh vistas: the Pluto mission will go on to probe other small bodies in the Kuiper Belt.
And on 29 November it announced that it had chosen for further development the proposal from a team led by Alan Stern, a planetary scientist at the Southwest Research Institute in Boulder, Colorado. Called 'New Horizons', the mission could launch in January 2006.

The spacecraft, to be built and operated by the Applied Physics Laboratory at Johns Hopkins University in Baltimore, would examine Pluto and its moon Charon. It would then go on to explore other small bodies within the Kuiper Belt.

But to survive beyond next year, the mission must pass a NASA technical and fiscal review, and secure long-term funding from Congress. The White House requested no funds for a Pluto mission in 2002, and the project went ahead only after a last-minute congressional appropriation of $\mathbf{\$ 3 0}$ million.

If it launches in 2006, the spacecraft will reach Pluto between 2014 and 2018, depending on the launch vehicle selected. On board will be equipment to characterize the geology and map the surface composition of Pluto and Charon. The planet's atmosphere will also be assessed.

New Horizons beat the mission proposal that would have been managed by the Jet Propulsion Laboratory (JPL) in Pasadena, California, which usually runs NASA's planetary science missions. Originally, NASA had wanted the JPL to develop both the Pluto mission and a mission to Jupiter's moon Europa. But when the costs for the Europa orbiter mushroomed, the two projects were 'decoupled', and the Pluto mission was opened to outside competition. 